\title{
SABERES E PRÁTICAS DA ENFERMAGEM NA UTILIZAÇÃO DO CATETER CENTRAL DE INSERÇÃO PERIFÉRICA EM NEONATOLOGIA
}

\section{KNOWLEDGE AND PRACTICES OF NURSING IN THE USE OF THE CENTRAL PERIPHERAL INSERTION CATHETER IN NEONATOLOGY}

\section{CONOCIMIENTOS Y PRÁCTICAS DE ENFERMERÍA EN EL USO DEL CATÉTER CENTRAL DE INSERCIÓN PERIFÉRICA EN NEONATOLOGÍA}

Leonardo Bigolin Jantsch ${ }^{1}$, Eliane Tatsch Neves ${ }^{2}$, Maria Ribeiro Lacerda ${ }^{3}$.

\section{RESUMO}

Objetivo: Descrever os saberes e as práticas que sustentam o manejo do cateter central de inserção periférica pela equipe de enfermagem em terapia intensiva neonatal. Método: Trata-se de um estudo qualitativo que teve como participantes 11 integrantes da equipe de enfermagem de uma Unidade de Terapia Intensiva Neonatal. Os dados foram coletados, por meio de entrevistas semiestruturadas, posteriormente, transcritos sob dupla transcrição e submetidos à análise temática de conteúdo com discussão teórica, a partir dos padrões do conhecimento em Enfermagem. Resultados: Foram descritas quatro categorias que representam os saberes e práticas: indicativos para inserção na prática neonatal; cuidados que precedem o procedimento de inserção; cuidados que contribuem para a manutenção da terapêutica; indicativos para retirada precoce do cateter: o sofrimento com o retorno da prática periférica. Conclusão: Os saberes da Enfermagem emergem e estão pautados no fazer cotidiano, constituindo-se práticas empíricas em prol da qualificação do cuidado.

Descritores: Enfermagem Neonatal; Cuidados de Enfermagem; Conhecimentos, Atitudes e Prática em Saúde.

\section{ABSTRACT}

Objective: To describe the knowledge and the practices supporting the management of the central catheter of peripheral insertion by the nursing team in neonatal intensive care. Method: This is a qualitative study involving 11 members of the nursing team of a Neonatal Intensive Care Unit. Data were collected through semi-structured interviews, later transcribed under double transcription and submitted to content thematic analysis with theoretical discussion based on the knowledge patterns in Nursing. Results: Four categories representing the knowledge and practices were described: indicative for insertion in the neonatal practice; care that precedes the insertion procedure; care that contributes to the maintenance of therapy; indicative of early withdrawal of the catheter: suffering with the return of peripheral practice. Conclusion: Nursing knowledge emerges and is based on daily routine, constituting empirical practices for the qualification of care.

Descriptors: Neonatal Nursing; Nursing Care; Health Knowledge, Attitudes, Practice.

\section{RESUMEN}

Objetivo: Describir los conocimientos y las prácticas que sustentan el manejo del catéter central de inserción periférica por el equipo de enfermería en terapia intensiva neonatal. Método: Se trata de un estudio cualitativo que tuvo como participantes 11 integrantes del equipo de enfermería de una Unidad de Terapia Intensiva Neonatal. Los datos fueron recolectados por medio de entrevistas semiestructuradas, posteriormente transcriptos bajo doble transcripción y sometidos al análisis temático de contenido con discusión teórica a partir de los patrones del conocimiento en Enfermería. Resultados: Se han descrito cuatro categorías que representan los conocimientos y las prácticas: indicativos para inserción en la práctica neonatal; los cuidados que preceden al procedimiento de inserción; cuidados que contribuyen al mantenimiento del tratamiento; indicativos para la retirada temprana del catéter: el sufrimiento con el retorno de la práctica periférica. Conclusión: Los saberes de la Enfermería emergen y están pautados en el hacer cotidiano, constituyéndose prácticas empíricas en pro de la calidad del cuidado.

Descriptores: Enfermería Neonatal; Atención de Enfermería; Conocimientos, Actitudes y Práctica en Salud.

${ }^{1}$ Doutor em Enfermagem. Professor Adjunto do Departamento de Ciências da Saúde da Universidade Federal de Santa Maria - UFSM/Palmeira das Missões. ${ }^{2}$ Pós-Doutora em Enfermagem. Professora do Departamento de Enfermagem da UFSM. ${ }^{3}$ Doutora em Enfermagem. professora permanente do programa de Pós-graduação em Enfermagem da Universidade Federal do Paraná.

Como citar este artigo:

Jantsch, LB, Neves ET, Lacerda, MR. Saberes e práticas na utilização do cateter central de inserção periférica em neonatologia. Revista de Enfermagem do Centro-Oeste Mineiro. 2019;9:e3299. [Access ]; Available in: . DOI 


\section{INTRODUÇÃO}

O corpo de conhecimento da Enfermagem vem se consolidando como Ciência, a partir de um movimento de construção de uma linguagem específica, atribuindo significado do seu saber para o ser e fazer ${ }^{(1)}$. Construir saberes para Enfermagem significa galgar em busca de novos conceitos, transpondo barreiras à procura de alicerces que embasem o desenvolvimento de teorias que sustentam o cuidado. Como fonte de construção teórica, a Enfermagem baseia-se no empirismo, visto que, muito do seu conhecimento provém do seu fazer ${ }^{(2)}$.

Diante das exigências diárias do cuidado, o enfermeiro constrói conhecimento próprio que, por vezes, limita-se ao seu ambiente de trabalho, implicando apenas naquela realidade. Na prática da Enfermagem, a construção ou apropriação do conhecimento, seja do vivido ou do científico, requer constante atualização e reflexão sobre o impacto de suas ações, na sua tomada de decisão. Nessa perspectiva, o conhecimento parte de dois conceitos: o conhecimento teórico, que contribui para tomada de decisão; e o conhecimento prático, que é incorporado no desenvolvimento das práticas de cuidado - saber prático $^{(3)}$.

Nesse contexto de cuidado, a utilização de diversas tecnologias, saberes e práticas de cuidados pré-natais, obstétricas e neonatais- vêm contribuindo para a diminuição da mortalidade de recém-nascidos, em especial, dos prematuros, considerados como a população mais vulnerável ao óbito neonatal precoce e, no primeiro ano de vida ${ }^{(4)}$. Muitos recém-nascidos em condição de prematuridade ou com outras afecções patológicas diversas, necessitam de terapia intravenosa, durante o seu tratamento na internação hospitalar. A adoção de tecnologias que qualifiquem o cuidado em terapia intravenosa é essencial para o sucesso na reabilitação neonatal ${ }^{(5)}$. Dentre essas tecnologias, destaca-se o Cateter Central de Inserção Periférica (PICC) como avanço tecnológico no cuidado intensivo neonatal ${ }^{(6)}$.

O PICC é um dispositivo intravenoso central que é inserido por uma veia periférica e com a ajuda de movimentos de inserção e do fluxo sanguíneo, tem sua extremidade alocada no terço distal da veia cava ${ }^{(7)}$. O respaldo legal para a prática de inserção do PICC, pelo Enfermeiro, encontra-se no Artigo 1 으 da Resolução no 258/2001 do Conselho Federal de Enfermagem (COFEN). Contudo, somente estão aptos aqueles que estiverem qualificados mediante capacitação específica para tal ${ }^{(8)}$. A legislação que legitima ao enfermeiro a inserção do cateter não permeia apenas a técnica de inserção em si, mas todo o processo que envolve a decisão de inserção, técnicas e condutas na inserção e manutenção, bem como na tomada de decisão para sua retirada. Nessa perspectiva, cabe ao Técnico de Enfermagem, assistir ao enfermeiro diante de procedimentos de sua competência, bem como administrar e realizar o cuidado de enfermagem na administração de medicações parenterais, seja por via periférica ou central ${ }^{(9)}$.

O enfermeiro possui autonomia legal e responde pelo processo de utilização do PICC, porém ainda há pouco conhecimento construído acerca das práticas de cuidado, embora exista um corpo de conhecimento científico que oriente algumas técnicas de cuidados. Os saberes e práticas da enfermagem, no contexto da terapia intravenosa com o PICC, ainda vive uma realidade em que: enfermeiros sem o título de capacitação e/ou habilitação para a indicação e inserção do PICC assumem o protagonismo desse cuidado; Enfermeiros e demais integrantes da equipe desconhecem os benefícios e indicações oferecidas pelo cateter; Falta de investimento da fonte mantenedora das unidades hospitalares; Equipes com baixa adesão às práticas de Educação Permanente nos serviços de saúde ${ }^{(10)}$.

Além desses entraves vividos, sob um contexto geral, na neonatologia ainda existem particularidades tais como: Maior risco de infecções, critérios exclusivos de indicação e retirada, necessidade de inclusão familiar no cuidado, com corresponsabilização da família no processo e a analgesia e sedação. Essas situações reforçam a necessária discussão acerca dos conhecimentos e práticas de cuidado, e sua implicação direta no cotidiano da terapia intravenosa neonatal ${ }^{(11)}$.

O corpo de conhecimento da Enfermagem, como ciência do cuidado, fundamenta-se em padrões de conhecimento descritos, inicialmente, por Carper, em $1978^{(12)}$. Os quatro padrões por ela apresentados são: empírico, estético, pessoal e ético ${ }^{(12)}$. Eles pretendem organizar o conhecimento teórico/prático do fazer e saber em Enfermagem com o intuito de contribuir para a sua construção em uma profissão que busca visibilidade e reconhecimento como Ciência.

O conhecimento empírico, pautado no saber científico, fundamenta-se em pesquisas científicas que visam à descrição dos fenômenos 
de interesse para os mais diversos campos do saber. $O$ saber estético está intimamente relacionado à criação e/ou apreciação de uma expressão singular, particular e subjetiva de possibilidade para prestar o cuidado. $O$ saber pessoal detém-se ao processo de empatia, no momento em que o enfermeiro se coloca no lugar daquele que ele cuida. Já o saber ético, vai muito além do que se estabelece no código de ética, ele se sustenta a partir do que é certo e deveria ser realizado, na perspectiva de quem cuida e quem é cuidado ${ }^{(12)}$.

Nessa perspectiva, estudos que buscam consolidar o fazer e o saber da enfermagem na utilização do cateter central de inserção periférica, tendo em vista, a discussão desses com os padrões do conhecimento da enfermagem descritos por Carper $(1978)^{(12)}$, pretendem contribuir para a consolidação da ciência da Enfermagem Neonatal. O saber e o fazer da equipe de enfermagem implica, diretamente, na realização dos processos de enfermagem, o qual envolve as diferentes categorias profissionais. Nessa perspectiva, discutir o saber que guia o fazer dos profissionais da enfermagem, dentro dos processos, é essencial para consolidação das práticas do cuidado $^{(13)}$. Dar voz às distintas categorias profissionais na enfermagem, e aproximá-las aos Padrões do Conhecimento ${ }^{(12)}$ permite ampliar o olhar sobre o cuidado e determinar as potencialidades de cada profissional, dentro das competências legais.

Para tanto, objetivou-se descrever os saberes e as práticas que sustentam o manejo do cateter central de inserção periférica, pela equipe de enfermagem, em terapia intensiva neonatal.

\section{MÉTODO}

Trata-se de um estudo descritivo, exploratório de abordagem qualitativa que utilizou como referencial teórico os Padrões do Conhecimento da Enfermagem, de acordo com Carper (1978) $)^{(12)}$.

Foram participantes do estudo Enfermeiros e Técnicos de Enfermagem que possuíssem, no mínimo, um ano de experiência em um serviço de Terapia Intensiva Neonatal, de um hospital de ensino do sul do Brasil. O cenário do estudo, trata-se de um serviço referência para região central do Rio Grande do Sul e utiliza o cateter PICC há 18 anos. A partir desses critérios, foram selecionados sete enfermeiros e 24 técnicos de enfermagem para participarem do estudo. A partir dessa seleção, sortearam-se os prováveis participantes, e estabeleceu-se uma ordem para o início dos convites e realização das entrevistas O encerramento do período de coletada de dados, foi dado quando alcançada a saturação teórica, por meio da repetição e similaridade das entrevistas. Essa saturação aconteceu apenas com a categoria de Técnicos de Enfermagem. Assim, participaram do estudo 11 integrantes da equipe de enfermagem, sendo cinco enfermeiros e seis técnicos de enfermagem. Duas enfermeiras não aceitaram participar do estudo.

A seleção da equipe de enfermagem [enfermeiros e técnicos de enfermagem] como participantes da pesquisa, justifica-se pelos seguintes critérios: Enfermeiros: Profissionais responsáveis pela prática Intravenosa, responsáveis pela indicação, inserção, manutenção e retirada do cateter. Técnicos de Enfermagem: Profissionais que possuem responsabilidade, sob supervisão do enfermeiro, na manipulação e manutenção do cateter, sendo os primeiros a identificar potencialidades e problemas relacionados à terapêutica. Também ouvir essa categoria profissional e discutir seus saberes e práticas, contribui para a construção do cuidado de enfermagem, ao entendimento de que o fazer, do Técnico de Enfermagem, é inerente ao saber prático.

Para a produção dos dados, foram realizadas entrevistas semiestruturadas, no segundo semestre de 2014. A entrevista semiestruturada, para categoria dos Técnicos de Enfermagem era pautada sob os seguintes questionamentos: $O$ que você sabe sobre o Cateter Central de Inserção Periférica? Ao auxiliar - Enfermeiro na Inserção do Cateter, quais os cuidados você considera essencial? Quais os cuidados que você tem para a manutenção segura do cateter? Para a categoria dos Enfermeiros, em síntese, as questões da entrevista semiestruturada foram: Quais os critérios de indicação para inserção do cateter? Quais práticas você utiliza antes do procedimento de inserção? Para o procedimento de inserção quais são os cuidados essenciais? Quais são as práticas de manutenção segura? Indicativos de retirada e cuidados? As entrevistas foram gravadas por meio de gravador eletrônico, tiveram tempo médio de 15 minutos (mínimo 6 minutos e máximo de 32 minutos) e, posteriormente, transcritas na íntegra, sob dupla transcrição e revisão independente. Após transcritos, o corpus do estudo foi submetido à 
análise de conteúdo temática, seguindo-se as três etapas estabelecidas ${ }^{(14)}$.

O anonimato dos sujeitos foi preservado, por meio da identificação alfanumérica utilizando-se a letra E para Enfermeiras e $\mathrm{T}$ para Técnicos da Enfermagem, seguida de sequência numérica aleatória das entrevistas (E1, E2, E3; T1, T2, T3...).

O desenvolvimento do estudo atendeu às exigências da Resolução 466/2012, que envolve pesquisas com seres humanos, sendo aprovado pelo Comitê de Ética em Pesquisa da Universidade Federal de Santa Maria sob o número de protocolo: CAAE 13149613.3.0000.5346, sob número de parecer: 556415.

\section{RESULTADOS E DISCUSSÃO}

A partir dos enunciados, foi possível realizar a categorização temática, por meio da recorrência de temas e por afinidade temática que, ao final, deram origem a quatro categorias que serão apresentadas a seguir.

\section{Indicativos para inserção do PICC na prática neonatal}

Os indicativos utilizados pelos enfermeiros para inserção do PICC estão presentes nos argumentos:

"Primeiro aquele que vai ter tempo de internação prolongada, o uso de NP [Nutrição Parenteral] ou o uso prolongado de antibiótico, acho que é a maior razão! Um nenê prematuro ou então prematuridade extrema! [...] por experiência mesmo, esses nenês que vem com prognóstico de cirurgia intestinal, é um bebe que vai usar nutrição parenteral, muito tempo!" (E3)

"Se um nenê bastante prematuro, que vai precisar de terapia IV, por muito tempo, quando ele tem antibiótico acima de seis dias, quando o nenê precisa de nutrição parenteral, ou alguma solução bastante concentrada, e algumas medicações que são irritantes, com pH muito básico ou hiperosmolar, que precisam de um acesso central [...] tem outras soluções, dopa [dopamina]... fentanil [fentanila], utilizados para nenês graves, que estão instáveis, já é indicativo!"(E8)

"[...] prematuridade extrema, prematuro também, não precisa ser extremo! Baixo peso, RN instável, grave, que faz uso de nutrição parenteral, inotrópicos, antibioticoterapia, hidratação[...]" (E10)
"[...] se ele for também um nenê ruim de veia, logo nos primeiros dias de internação, geralmente filhos de mãe diabética, ou que são difíceis de veia, tem uma rede venosa prejudicada, são difíceis de tu enxergar para puncionar, as vezes nascem e se mantém edemaciados, se você não indicar um PICC logo, você perde possibilidades depois pelo esgotamento da rede venosa"(E1)

O saber empírico permeia essa categoria, em que, em síntese, os participantes destacaram três principais motivos sugestivos para a inserção do PICC: fatores diagnósticos, morfológicos e clínicos. No que tange os fatores diagnósticos, são considerados fatores para a instalação do cateter no presente serviço do estudo: a Prematuridade, Prematuridade extrema, baixo peso (inferior a 2500 g) e aqueles recém-nascidos (RN) com prognóstico de procedimentos cirúrgicos, em especial as cirurgias intestinais, em decorrência da longa permanência de nutrição parenteral. As características de fluidos, tais como antibioticoterapia prolongada bem como infusões hiperosmolares, vesicantes e irritantes, também são fatores considerados no momento de indicação do cateter.

Fatores indicativos para a inserção do cateter são estabelecidos por diversos fatores relacionados à terapêutica utilizada. Estudos corroboram com os achados e descrevem que a Prematuridade e o Baixo Peso são os seus principais indicativos. Corroborando com os demais autores, neste estudo, a utilização de nutrição parenteral é o fator mais citado como indicativo de inserção do PICC, bem como a antibioticoterapia prolongada, ambas decorrentes também das características de alta osmolaridade e alterações de $\mathrm{pH}^{(7)}$.

Quanto aos indicativos morfológicos, estes estão associados à RN com rede venosa prejudicada e/ou com pouca visualização, considerado os RN "ruim de veia" (E1). Geralmente, estes RN são filhos de mãe diabética, em razão da característica de Grandes para Idade Gestacional (GIG) e a ruim visualização venosa periférica. Além destes, os sujeitos consideram que todos aqueles que "[...] são difíceis de veia, tem uma rede venosa prejudicada, são difíceis de tu enxergar para puncionar [...]" (E1), são indicativos precoces de inserção.

Quanto às características morfológicas, os $\mathrm{RN}$, com difícil rede venosa, representam para a prática periférica um desafio frequente e um fator estressante para a equipe, sempre que a 
punção periférica deva ser realizada. A perda do acesso venoso periférico é uma constante no cotidiano da UTIN e a necessidade de nova punção venosa e manutenção de acesso seguro, utiliza cerca de $75 \%$ do tempo de atuação do enfermeiro nesse serviço. Autores destacam que, grande parte do tempo gasto na terapia intensiva neonatal é envolvida com a terapia intravenosa ${ }^{(15)}$. Assim, o PICC representa conforto e facilidade de implantação de uma terapia intravenosa segura e que não represente estresse para a equipe e otimize tempo.

As características clínicas também são fatores sugestivos para a utilização do cateter PICC. Considera-se que um RN clinicamente grave, necessite acesso venoso central, e o PICC é considerado como primeira opção. A condição clínica grave, geralmente encontra-se associada ao longo período de internação, bem como características peculiares dos fluidos a serem administrados. Os três principais fatores indicativos de inserção estão associados a longo período de internação, bem como às características fisiológicas e farmacológicas, e são considerados indicativos isolados ou associados para inserção.

Ainda, nesse contexto do processo de indicação do PICC, identifica-se o saber ético em enfermagem pelo compromisso ético dos profissionais: "[...] antes de inserir o PICC eu preciso saber ou prever o tempo que ele vai ficar aqui dentro da UTI, porque de repente tu vai passar um PICC, tu vai expor a criança à terapia central [reconhece os riscos de uma terapia intravenosa central], e daqui a um pouquinho tu vai ver que era uma criança que não precisava que vai ficar aqui quatro ou cinco dias só!" (E2). É implícito nos enunciados o compromisso ético e moral da equipe de enfermagem com o sucesso na terapia intravenosa neonatal, por meio da construção do saber empírico, que guia os preditores de inserção, sustentados por uma prática segura. Os enfermeiros reconhecem que o PICC, por ser um acesso central, representa riscos e que sua indicação deve preceder de indicativos específicos.

Os critérios de indicação do PICC na prática neonatal estão estabelecidos pelo saber empírico e ético ${ }^{(12)}$, e os enfermeiros demonstraram conhecimento sobre as características dos fluidos a serem infundidos na terapia intravenosa e, como isso, se torna indicativo para a inserção. Os participantes demonstram, ainda, um saber construído por meio de sua vivência na prática, quando citam as características morfológicas dos RN e os consideram "ruim de veia"(E1).

\section{Cuidados que precedem o procedimento de inserção do PICC}

Após a decisão de inserção do cateter, os enfermeiros destacam práticas importantes, que precedem e, assim, possibilitam sucesso no procedimento de inserção. Estabelecer e manter o RN aquecido são considerados fatores importantes e que facilitam o procedimento de instalação. Os participantes consideram temperatura axilar ideal para iniciar o procedimento de $37,5 \circ \mathrm{C}$. A afirmação dessa prática se dá a partir dos enunciados:

"Está Aquecido, pra mim um nenê aquecido é em torno de 37 graus... primeiro eu deixo aquecer ele bem, 37으... 37,5ㅇ... bem quentinho, porque a gente vai expor [abrir incubadora] o nenê ali, ele vai esfriar rapidinho!" (E2)

“Temperatura de...37,5으 De 3709 C, se é um bebê que não está grave, tem que ser 37,5 으 pra ti ter um sucesso! Porque tu abre a incubadora ele se gela! Quando tu passa a clorexidina ele se esfria mais um pouquinho!" (T3)

"Nenê estar aquecido, é primeira coisa [...]Aumentar a temperatura da incubadora antes... tem que estar mais de 37,5으 a temperatura[axilar] [...] ele se gela muito rápido, né!?" (T6)

"Primeira coisa o nenê tem que estar bem aquecido! Acima de 37,5, o nenê tem que estar bem aquecido! (...) e isso acontece por causa da dilatação dos vasos!" (E9)

"O nenê tem que estar bem aquecido, temperatura mais ou menos 37,5 , se ele tiver um nenê friozinho, não tem como visualizar a veia, dá vasoconstrição, aí não enxergamos e o cateter demora a progredir ou mesmo nem progride e perdemos o PICC [...]." (E11)

"O nenê deve estar bem aquecido, temperatura mais ou menos $37,5 \circ \mathrm{C}$, se ele estiver friozinho, não temos como visualizar a veia, dá vaso constrição e ainda tu abres a incubadora e ele resfria mais." (T7).

A verificação da temperatura axilar é o marco inicial para iniciar o procedimento. 0 controle térmico se dá a partir do ajuste da incubadora do RN. Segundo a equipe de enfermagem, uma temperatura adequada contribui para vasodilatação periférica, o que facilita a visualização venosa para punção e 
progressão do cateter. Cabe destacar o necessário controle rigoroso da curva térmica, visto que alterações como hipertermia ou hipotermia, além de prejudicar o RN, prejudicam a visualização venosa e o retorno venoso periférico, dificultando a progressão do cateter. Esse saber, empírico ${ }^{(12)}$, define-se, à medida que conhecem as consequências da vasoconstrição e vasodilatação para visualização venosa e progressão do cateter.

A intensa preocupação da equipe, com a temperatura do $\mathrm{RN}$, se deve à abertura da incubadora para o procedimento e, por consequência, a diminuição da temperatura do ambiente a que o RN ficará exposto. No que tange à temperatura inicial de $37,5 \circ \mathrm{C}$ e a manutenção desta, durante o procedimento, é um saber construído pela experiência prática da equipe, conforme os enunciados supracitados.

A vasoconstrição, que acontece quando o RN está hipotérmico, pode dificultar a progressão do cateter ${ }^{(16)}$. A prática de manter o RN aquecido permite uma melhor visualização da veia para punção, por meio da vasodilatação periférica, o que contribui para o sucesso na punção, bem como na progressão do cateter. O aumento da temperatura da incubadora resulta na vasodilatação periférica e na diminuição do retorno sanguíneo ${ }^{(17)}$. Assim, uma veia com maior fluxo sanguíneo apresenta-se mais visível para punção e, durante a progressão do cateter, o vaso encontra-se com um maior volume sanguíneo, o que pode colaborar com a abertura das válvulas sanguíneas e facilitar a progressão do cateter.

Além do controle térmico, outro cuidado estabelecido antes do procedimento de inserção é a realização de medidas de conforto para o RN, com a finalidade de acalmá-lo para o procedimento e prover analgesia, visto que a inserção do PICC é considerada pelos participantes como um procedimento doloroso. A realização do procedimento em um RN agitado, choroso é fator que contribui para dificuldades no procedimento.

"[...]o nenê, na verdade, ele sente dor, se achar necessário, fazer medicação pra dor eu faço!, só tenho que tomar um pouco de cuidado para os bebes que não estão com tubo, o risco de pressão respiratória." (E2)

"[...] avaliar o estado do bebê, ver se este nenê precisar fazer algum tipo de sedação, porque tem nenê que chora e é agitado, isso dificulta o procedimento!" (T5)
"[...] algumas, a [nome de uma enfermeira] gosta do nenê bem quietinho, com dimorf, [morfina] sempre uma medicação, o dimorf que eles [médicos] prescrevem, mas assim, acho que se uma outra pessoa acalmar, ficar ali com o dedinho de luva [sucção não nutritiva] [...] também isso é importante! $\mathrm{E}$ isso ajuda! Acho que ele é bom, pra manter o paciente mais quietinho não chorando muito não!" (T4);

"Deixa ele bem quentinho! Tem que estar bem calminho! Dar glicose [glicose 25\%] antes ou se tem alguma medicação prescrita."(T7)

"[...] medicação para dor, porque é um procedimento creio que seja dolorido, como uma punção periférica. A gente usa geralmente dimorf, [morfina], que o médico prescreve! Para os nenês mais agitados é feito midazolan, os bebês mais agitados, os nenês que tu não tens como conter eles, daí para o procedimento a gente faz midazolan, para organizar o nenê! Pra um nenê que não está entubado, não dá pra fazer muita medicação, então tem que enrolar [Swaddling] ele, acalmar, de preferência que ele durma!" (E11)

A prática farmacológica mais utilizada no serviço é a administração de morfina IV, por meio da prescrição médica. Há uma preocupação, no que tange à utilização de opioides como medida analgésica, em razão de possíveis complicações, o que se estabelece como um compromisso ético da equipe. No que tange às medidas não farmacológicas utilizadas, cabe destacar a sucção não nutritiva, com dedo enluvado, a administração de glicose $25 \%$ por via oral e o swaddling - enrolamento, são consideradas pela equipe, práticas eficazes e frequentemente utilizadas.

Práticas farmacológicas de manejo da dor, em terapia intensiva neonatal, correspondem a apenas 3,4\% das medidas de controle da dor no RN, o restante corresponde a práticas não farmacológicas. Quanto a essas práticas, é possível perceber que as medidas não farmacológicas estão presentes no cotidiano de cuidado na inserção do PICC e há preocupação e compromisso por parte da equipe. A prática de analgesia farmacológica para a inserção do PICC tem a finalidade primordial de acalmar o RN para sucesso no procedimento, e não, diretamente, para medidas de conforto ${ }^{(21)}$. Estudos destacam e corroboram que o risco no uso de analgesia farmacológica, em caso de opioides ou fentanila, identificado pelos participantes como possibilidade, existe e que deve ser utilizado com 
cautela, principalmente para RN não entubados. Existe uma variada prática de sedação e analgesia, pela qual se requer utilização de cautela, visto que existem relação dessa utilização com maior tempo de ventilação em RN entubados e maior número de dias de internação ${ }^{(19)}$.

No que tange à administração de glicose $25 \%$ por via oral para prática da analgesia, recomenda-se administrar um $\mathrm{ml}$ de solução glicose $25 \%$, de um a dois minutos antes da realização do procedimento, e pode-se utilizar a sucção não nutritiva como medida auxiliar, o que contribui para a eficácia na prática. A sucção com glicose e sacarose são práticas não farmacológicas muito utilizadas no controle da dor e são consideradas eficientes e seguras ${ }^{(18,20)}$. Estudo ainda aponta que, quando comparados à prática farmacológica com paracetamol intravenoso e a sucção com sacarose, a sucção se mostrou mais efetiva na redução da dor em procedimentos com $\mathrm{RN}^{(20)}$.

A sucção não nutritiva é considerada uma prática utilizada conforme rotinas institucionais, e representa percentuais que variam de $34 \%$ a $5 \%$ das medidas realizadas de manejo da dor. Ela não contribui diretamente para a redução da dor, por meios fisiológicos, mas, sim, ajuda a reorganização do RN diante da situação de estresse a que está exposto e, assim, minimiza as repercussões fisiológicas e comportamentais da dor ${ }^{(20)}$.

É incipiente afirmar que a prática farmacológica ou não farmacológica de controle da dor do RN na inserção do PICC seja realizada, exclusivamente, com o intuito de prover conforto ao RN, ou de mantê-lo calmo durante o procedimento. Entretanto, esta é uma preocupação presente e uma prática recorrente no serviço cenário do estudo.

A prática da analgesia farmacológica ou não, no procedimento de inserção do PICC, está pautada em um saber pessoal ${ }^{(12)}$, pois há uma inferência da experiência pessoal na prática realizada; compromisso ético ${ }^{(12)}$, a medida que reconhece-se que paciente apresenta dor, durante o procedimento, e realiza práticas analgésicas; e empírico ${ }^{(12)}$, quando retratadas as complicações/efeitos colaterais das práticas farmacológicas. A enfermagem predita e reconhece os entraves na prática de inserção, e, para isso, estabelece um cuidado individualizado e singular, diante do procedimento, visto que se utiliza das tecnologias de analgesia, reconhece os seus benefícios e garante um cuidado humanizado na diminuição da dor e, ainda, favorece o sucesso no procedimento, na medida em que acalma o RN.

\section{Cuidados que contribuem para manutenção da terapia intravenosa por meio do PICC}

Cuidado que contribui para a manutenção do PICC refere-se a uma técnica adequada da troca do curativo no sítio de inserção do cateter, bem como uma boa estabilização deste. Algumas características essenciais no curativo são destacadas: bordas íntegras, que não descolem, sem umidade ou secreção no sítio de inserção e uma boa fixação, a fim de que não ocorra tração acidental. Essa característica é percebida quando: "Do curativo, que quando ele está começando a ficar solto tem que trocar!" (E4) "[...] [curativo] se tiver sujo, molhado, descolando, até no segundo ou terceiro dia já tem que trocar, depende da apresentação do curativo" (E5)

"[...] faz o curativo, faz a limpeza com clorexidina, espera secar coloca o transparente [curativo filme transparente], depois do transparente eu prendo a borboleta, geralmente com o próprio transparente. É um micropore ${ }^{\circ}$, aí depois um "esparadrapinho" pra fazer a gravata, a gravata deve grudar no micropore e não no transparente, porque se não tu vai rasgar tudo...depois outro micropore em cima com a data, pronto o curativo bem vedado, bem fechado e pronto tu pode puxar que ele não vai sair, [...] eu só prendo pra ter uma segurança, as mães pegam no colo, às vezes, o nenê e pode puxar [...]." (E1)

A prática da realização do curativo se estabelece, por meio da experiência pessoal de cada enfermeiro, bem como na singularidade de cada paciente para avaliação e realização da melhor e mais apropriada cobertura. A manutenção do curativo representa não apenas a cobertura do cateter, mas sim a manutenção do cateter, como conservação da terapêutica intravenosa. Essa relação pode ser percebida no enunciado:

Ele não pode ter sujidade, não pode estar solto, não pode ter umidade [...] se tu vê que esta sujo tem que ser trocado, porque pra mim aquilo ali é um meio de cultura. Se ele está sempre solto, um curativo que não é bem feito é um dos risco de perda de PICC, por que tu encontra PICC dentro da incubadora, solto? Porque não foi fixado o curativo! E aí é o enfermeiro quem faz! A gente perde PICC por curativo mal feito, 
descolando, aí quem se prejudica é o nenê que perde um acesso importante no tratamento." (E3)

A manutenção do cateter, por meio do curativo, garante uma adequada estabilização do cateter, além de dar papel importante na proteção do sítio de inserção. Avaliar os sinais flogísticos no sítio de inserção do PICC, como a presença de secreções e sujidade, é um saber e prática que permeia a avaliação da manutenção do PICC. Os participantes do estudo sugerem algumas características como: sujidade, umidade e secreção como contribuintes para o aumento do índice de infecção. Orientações dos Centros de Controle e Prevenção de Doenças $(C D C)^{(21)}$ estabelecem que o curativo filme, quando limpo, possa ser mantido em RN, por um período de até 10 dias, a fim de diminuir a manipulação desse cateter e também as complicações e lesões que esses adesivos podem causar à pele do RN.

A manutenção do cateter se faz necessária para uma permanência segura e duradoura do cateter, a fim de que sua retirada precoce não seja necessária, visto que, não há tempo máximo de permanência do cateter ${ }^{(25)}$. Essa avaliação das condições do curativo é responsabilidade de toda a equipe de enfermagem e é estabelecida por um saber ético, na perspectiva de reconhecer a importância da troca e assepsia desse sítio de inserção, e, no saber empírico, moderado pela prática da avaliação e tomada de decisão para a realização do curativo.

Outro cuidado que se estabelece no cotidiano com o PICC, em cateteres neonatais, é a característica das medicações que, por ele, podem ser administradas, bem como a importante permeabilização do cateter com solução fisiológica $0,9 \%$, em turbilhonamento, "Pra manutenção do cateter, só com flush, lavando com $0,5 \mathrm{ml}$ de $6 / 6$ horas!"(E10). Os participantes destacam ainda que, se faz importante a permeabilização do cateter, em especial, naqueles com baixo fluxo de infusão (menor que $1 \mathrm{ml} / \mathrm{h}$ ) ou aqueles que mantém-se salinizados/heparinizados.

Outras evidências destacadas pelos participantes, quanto à utilização de medicamentos, pode ser percebida nos enunciados:

"[...]as medicações que não pode fazer, tipo fenobarbital, aquela cristaliza..., a fenitoína, né, lasix[furosemida], aquilo ali tu sabes que não pode fazer, como é que tu vai fazer no PICC, né, não! Não! Não! usar essas medicações [...]ah...esses hemoderivados, não instalar também." (T2)

"[...] falta um pouco de conscientização do pessoal, de lavar antes, lavar depois, não usar medicação que a gente tem conhecimento eu tem risco de causar obstrução, hidantal [Fenitoína], diazepam,[...] já aconteceu, de se insistir que o nenê estava péssimo de veia e não ia puncionar periférico e fazer no cateter, terminar de fazer e obstruir! (E4)

A categoria estabelece os padrões do conhecimento definidos por Carper, à medida que considera o padrão empírico quando os enfermeiros utilizam dos protocolos internacionais ${ }^{(21)}$ para indicação/realização dos curativos, bem como a contraindicação de infusão de hemocomponentes por cateteres neonatais; saber ético no compromisso de manter, por maior tempo, o PICC como tecnologia de cuidado de forma segura; saber estético, implícito na singularidade no fazer, por meio de práticas individuais de cuidado e manutenção do cateter [curativo]; pessoal, explícito no vivido, por meio da decisão de não administrar alguns medicamentos, por risco de obstrução ou demais complicações.

\section{Indicativos para retirada precoce do cateter: o sofrimento com o retorno da prática periférica}

Os critérios para a retirada estão estabelecidos pelo padrão do saber ético em que a complexidade de julgamentos morais, em retirar ou não retirar, exige uma compreensão do que seja bom e correto para o RN.

"A retirada do PICC geralmente é confirmação de infecção, quando está confirmado! Já fizeram a hemocultura, já confirmou que era do PICC, ou quando deu fungo na hemocultura a gente retira... quando tem secreção a gente retira, secreção na inserção, quando tem piora clínica evidente, quando tem uma piora muito intensa se retira o PICC e nem dá tempo de coletar [...]" (E4).

Os principais motivos de retirada do cateter, antes do término da terapêutica, estão, em sua maioria, relacionados à: Infiltração, devido posicionamento em linha média ou periférica; ruptura do cateter; suspeita ou confirmada infecção relacionada ao cateter, destacando a retirada por infecção como o principal motivo no serviço.

Estudos que revelam que, quanto maior $o$ número de dias de utilização do PICC, maior a incidência de infecções relacionadas à terapia e, 
assim, orientam de forma empírica a necessidade da retirada precoce do cateter, quando confirmada infecção ou piora clínica iminente ${ }^{(15,22)}$. Assim, a prática de retirada precoce, se estabelece de forma empírica, por meio das indicações já expressas na literatura que orientam a prática do cuidado.

A literatura destaca que há uma diversidade de práticas adotadas em protocolos científicos e institucionais que, tanto concordam com as evidências quanto se apresentam discordantes aos achados científicos ${ }^{(23)}$. Esses resultados permitem diversas interpretações quanto à utilização de protocolos ou práticas assistenciais, que muito são orientadas pelo saber empírico e estético realizado pelo enfermeiro.

A enfermagem identifica os fatores e reconhece a necessidade de retirada precoce do cateter. Essa prática reflete sofrimento tanto para a equipe quanto para o $\mathrm{RN}$, em decorrência do retorno para a terapia periférica. Esses sentimentos ficam evidentes nos enunciados:

"Para tirar um PICC, meu deus do céu, é um investimento da gente em tirar um PICC, então eu questiono [...] tens certeza absoluta? Nossos argumentos [enfermeiras] são melhores! [Risos] [...] eu sou muito chata nesse sentido! Porque é muito investimento tu colocar um PICC, é muito investimento! De dinheiro, do risco que tu expões a criança, da gente ficar em cima [procedimento de inserção], do estresse danado, para as vezes conseguir passar um PICC! Vamos avaliar bem avaliado para retirar esse PICC! Quando tem que tirar um PICC antes, eu sempre penso onde foi que erramos? Em que momento do processo aconteceu o erro, se foi infecção, obstrução, ruptura..." (E2)

"A enfermagem é um pouco resistente para retirada do PICC e os médicos são mais de retirar! Qualquer piora clínica retira o PICC [médicos]... Porque a enfermagem sabe o que é a dificuldade de passar um PICC, a dificuldade de às vezes de puncionar e a enfermeira, "estava com a estrela" e consegue passar um PICC naquele nenê que já estava difícil até de punção periférica, então a gente tenta preservar e sabe que aquele nenê precisa daquele acesso pra fazer antibiótico, vai ter mais tempo de nutrição parenteral, vai ter bastante internado... As vezes somos resistentes até demais.... Essa resistência da enfermagem no retirar vem de muitas vezes da dificuldade de passar, o quanto é triste pro nenê estar toda a hora sendo submetido a dor, a manipulação, a enfermeira tem muito mais tranquilidade em trabalhar, quando ele sabe que tem um acesso seguro, então ela vai tentar segurar o PICC."(E8)

A retirada do cateter se estabelece também em um sentimento de desvalorização do seu fazer e do seu saber, à medida que a retirada é considerada uma falha no seu cuidado. Significa para o enfermeiro que seu cuidado foi insuficiente, esse sentimento gera primeiro a negação da retirada e posterior sentimento de culpabilização. Ainda, um dos motivos que levam ao estresse é a necessária punção venosa periférica, em especial em $\mathrm{RN}$ com difícil rede venosa, considerada, pelos participantes, principal fator estressante na terapia intensiva neonatal.

As práticas que levam à retirada precoce de cateteres PICC corroboram com os achados e provêm de erros no processo, que são, por vezes, resultantes de infecções relacionadas aos cateteres, obstruções e ruptura ${ }^{(29-30)}$. A manutenção é etapa crucial da utilização do PICC, no que se refere, principalmente, aos cuidados que proporcionem uma maior durabilidade do dispositivo, evitando a perda do cateter antes do fim da indicação( ${ }^{(15)}$.

Ainda, é possível destacar o reconhecimento do sofrimento do RN com a necessidade de retorno para a prática periférica, o retorno da punção venosa periférica e os riscos dessa prática, como a infiltração e administração de medicamentos de via central. Reconhecer a prática da retirada do PICC reflete ao enfermeiro o conhecimento pessoal, na medida em que se coloca no lugar do seu paciente, e assim, remete dor e desconforto que a terapia intravenosa pode apresentar. Reconhecer esse compromisso o faz detentor de um compromisso ético com o cuidado, pautado em um saber pessoal, de autoconhecimento e empatia.

\section{CONSIDERAÇÕES FINAIS}

Os saberes e práticas da equipe de enfermagem denotam que os padrões do conhecimento estão presentes na prática neonatal e que permeiam os cuidados de enfermagem na terapia intravenosa com a utilização do PICC.

Destaca-se, ancorando-se no padrão empírico e ético os critérios indicativos para a utilização do cateter que partem das características dos $\mathrm{RN}$, por meio dos fatores: diagnósticos, morfológicos e clínicos. Antes de iniciar o procedimento, amparam-se nos padrões empíricos, pessoal e ético a manutenção do $\mathrm{RN}$ 
em temperatura de 37,5드 considerada temperatura ideal para a inserção, bem como a utilização de medidas analgésicas, com o intuito de acalmar o RN, durante o procedimento. As medidas analgésicas não farmacológicas mais usadas são a sucção não nutritiva, o enrolamento e a glicose $25 \%$. A manutenção do cateter, parte do princípio de práticas de assepsia na manipulação do cateter, estabilização do cateter, por meio de curativo integro e limpo, pautadas no conhecimento empírico, estético, pessoal e ético. Os indicativos de retirada precoce do cateter partem do princípio de obstrução, ruptura, e a principal: infecção relacionada ao cateter, implícitos no saber ético e empírico.

A descrição dos saberes e práticas da enfermagem na utilização do PICC, permite concluir que a Enfermagem possui um corpo de conhecimento construído e que vem sendo consumido pela Enfermagem. Construir conhecimento prático, que possa ser aplicado e adaptado em outras realidades, permite 0 fortalecimento da enfermagem neonatal na prática intravenosa. Conhecer os saberes e práticas do cuidado da enfermagem neonatal fortalece a construção do conhecimento que vai além do pensado/realizado de forma individual, podendo, assim, ser consumido por outras equipes/outros enfermeiros.

Reconhece-se como limitação do estudo a descrição de uma característica local das práticas e fazer, contudo, instiga-se a realização de novos estudos, em outros cenários, que busquem consolidar práticas e saberes do cuidado e assim fortalecer a ciência da enfermagem.

Os quatro padrões do conhecimento descritos por Carper são atuais/atuantes, na prática da enfermagem neonatal. São indissociáveis, e partem do princípio de que todo o saber, na prática intravenosa neonatal com o PICC, parte de um princípio original, seja ele empírico, ético, pessoal ou estético.

\section{REFERÊNCIAS}

1- Brito L, Sousa N, Alencar A, Rebouças V, Pinheiro $P$, Gonçalves Júnior J. Concepts, theoretical models and nursing theories: Integrative review. Int Arch Med. 2017;10(166):18. DOI: $10.3823 / 2436$

2- Barbosa LBA, Motta ALC, Resck ZMR. Os paradigmas da modernidade e pós-modernidade e o processo de cuidar na enfermagem. Enfermería Global 2015 [citado em 2 dez 2018]; 37:342-9.

Disponível

em: http://scielo.isciii.es/pdf/eg/v14n37/pt reflexion $\underline{2 . p d f}$

3- Vale EG, Pagliuca LMF, Quirino RHR. Saberes e práxis em enfermagem. Esc Anna Nery Rev Enferm. 2009;13(1):174-80. DOI: 10.1590/S141481452009000100024

4- Stensvold HJ, Klingenberg C, Stoen R, Moster D, Braekke K, Guthe HJ, et al. Neonatal morbidity and 1-year survival of extremely preterm infants. Pediatrics 2017;139(3):100-9.

DOI:

10.1542/peds.2016-1821

5- Lin HJ, Du LZ, Ma XL, Shi LP, Pan JH, Tong XM, et al. Mortality and morbidity of extremely low birth weight infants in the mainland of china: $A$ multi-center study. Chin Med J. 2015;128(20):2743-50. DOI: 10.4103/03666999.167312

6- Araújo FL, Manzo BF, Costa ACL, Corrêa AR, Marcatto JO, Simão DAS. Adherence to central venous catheter insertion bundle in neonatal and pediatric units Rev Esc Enferm USP 2017;51:1-8. DOI: 10.1590/S1980-220X2017009603269

7- Santo MKD, Takemoto D, Nascimento RG, Nascimento AM, Siqueira E, Duarte $C T$, et al. Peripherally inserted central venous catheters: Alternative or first choice vascular access? J Vasc Bras. 2017;16(2):104-12. DOI: 10.1590/1677$\underline{5449.011516}$

8- Brasil, Conselho Federal de Enfermagem (COFEN). Resolução no 258, 12 de julho de 2001. Rio de Janeiro: Cofen; 2001.

9-Brasil, Conselho Federal de Enfermagem (COFEN). Lei no 7.498/86, de 25 de junho de 1986. Dispõe sobre a regulamentação do exercício da Enfermagem e dá outras providências. Diário Oficial da União 1986.

10- Sá Neto JÁ, Silva ACSS, Vidal AR, Knupp VMAO, Barcia LLC, Barreto ACM. Nurses' knowledge of the peripherally inserted central catheter: Local realities and global challenges. Rev Enferm UERJ 2018;26:1-6. DOI: 10.12957/reuerj.2018.33181

11-Lui AML, Zilly $A$, França AFO, Ferreira $H$, Toninato APC, Silva RMM. Care and limitations in the management of the peripherally inserted central catheter in neonatology. Rev Enferm Cent-Oeste Min. 2018; 8:1-11. DOI: 10.19175/recom.v7i0.1918

12- Carper B. Fundamental patterns of knowing in nursing. Adv Nurs Sci. 1978;1(1):13-24. DOI: 10.1097/00012272-197810000-00004

13- Carvalho EC, Dalri MCB, Napoleão AA, Ramos LAR, Salvador M, Reis PED. The contribution of members of the nursing team to the nursing 
process according to nurses. Rev Min Enferm. 2008;12(1):71-8. DOI: $10.1590 /$ S008062342008000400006

14 - Bardin L. Análise de conteúdo. São Paulo: Edições 70; 2011.

15-Souza B, Rangel $R$, Alves $H$, Rodrigues VP, Dames DP, Dórea PE, et al. The knowledge of nurses in terms of the peripherally inserted central catheter: A descriptive study. Online Brazilian Journal of Nursing 2016 [citado em 2 dez 2018]; 15(1):21-31. Disponível em: http://www.redalyc.org/articulo.oa?id=36145397 $\underline{7003}$

16 - McSwain JR, Yared M, Doty JW, Wilson SH. Perioperative hypothermia: Causes, consequences and treatment. World J Anesthesiol. 2015;4(3):58-65. DOI: 10.5313/wja.v4.i3.58

17 - Aquinol WKM, Lopes MVO, Silva VM, Fróes NBM, Menezes APM, Almeidall AAP, et al. Accuracy of the defi ning characteristics in nursing diagnoses of Hyperthermia in newborns. Rev Bras Enferm. 2018;71(2):357-62. DOI: 10.1590/0034-7167-2017-0037

18 - Querido DL, Christoffel MM, Almeida VS, Esteves APVS, Andrade $M$, Amim Júnior $J$. Assistance flowchart for pain management in a Neonatal Intensive Care Unit. Rev. Bras. Enferm. 2018;71(Suppl 3):1281-9. DOI: 10.1590/00347167-2017-0265

19 - Carbajal R, Eriksson M, Courtois E, Boyle E, Avila-Alvarez $A$, Andersen RD, et al. Sedation and analgesia practices in neonatal intensive care units (EUROPAIN): Results from a prospective cohort study. Lancet 2015; 3(10):796-812. DOI: 10.1016/S2213-2600(15)00331-8

20 - Roofthooft DWE, Simons SHP, Lingen RAV, Tibboel D, Anker JNVD, Reiss IKH, et al. Randomized controlled trial comparing different single doses of intravenous paracetamol for placement of peripherally inserted central catheters in preterm infants. Neonatol. 2017;112:150-8. DOI: 10.1159/000468975

21 - Sharpe E, Pettit J, Ellsbury DL. A national survey of neonatal Peripherally Inserted Central Catheter (PICC) practices. Adv Neonatal Care 2013;13(1):55-74. DOI: 10.1097/ANC.0b013e318278b907

22 - Martín-Rabadán P, Pérez-García F, Flores EZ, Nisa ES, Guembe M, Bouza E. Improved method for the detection of catheter colonization and catheter-related bacteremia in newborns. Diagn Microbiol Infect Dis. 2017;87(4):311-4. DOI: 10.1016/i.diagmicrobio.2017.01.001
23 - Curan GRF, Rossetto EG. Interventions to decrease catheter-associated bloodstream infections in newborns: An integrative review. Texto Contexto-Enferm. 2017;26(1):1-9. DOI: 10.1590/0104-07072017005130015

24 - Tsai MH, Hsu JF, Lien R, Huang HR, Chiang CC, Chu SM, et al. Catheter management in neonates with bloodstream infection and a percutaneously inserted central venous catheter in situ: Removal or not? Am. J Infect Control. 2017;40(1):59-64. DOI: 10.1016/j.ajic.2011.04.051

25 - Van den Berg J, Astroom JL, Olofsson J, Fridlund $M$, Farooqi A. Peripherally inserted central catheter in extremely preterm infants: Characteristics and influencing factors. J Neonatal Perinatal Med. 2017;10(1):63-70. DOI: $\underline{10.3233 / N P M-16105}$

Nota: Artigo Extraído da dissertação de mestrado intitulada: Saberes e práticas da enfermagem na utilização do cateter venoso central de inserção periférica em neonatologia, defendida no Programa de Pós-Graduação em Enfermagem da Universidade Federal de Santa Maria (PPGENF).

Recebido em: 27/02/2019

Aprovado em: 19/09/2019

Endereço de correspondência:

Leonardo Bigolin Jantsch

Endereço: Av. Independência, 3751 - Vista Alegre CEP: 98300-000 - Palmeira das Missões /MG - Brasil

E- mail: Leonardo.jantsch@ufsm.br 